\title{
A two stage battery charger for EV charging applications
}

\author{
V. Kalyanasundaram, S. George Fernandez, K. Vijayakumar, S. Vidyasagar \\ Department of Electrical and Electronics Engineering, SRMIST, India
}

\begin{tabular}{l} 
Article Info \\
\hline Article history: \\
Received Dec 25, 2019 \\
Revised Feb 27, 2020 \\
Accepted Mar 12, 2020 \\
\hline
\end{tabular}

\section{Keywords:}

EV charging applications Electrical power industry Transportation sector MATLAB

\begin{abstract}
Electric power generation and consumption are indicating an unprecedented change in recent decades. Electrical power industry and transportation sector lie at the core of this development and hence this change. This change is one of the major causes of polluting environmental and global warming. So, to decrease the dependency on conventional fuels and greenhouse gas emissions, countries around the globe are actively finding alternative energy resources. It will help to develop clean and green energies to build a sustainable society. Simultaneously, energy utilization in the field of transportation is witnessing a change from fossil fuel to electricity-based fuel. Electrified transportation system is a solution to endorse sustainable energy development and addressing environmental pollution, global warming issues. In this paper, an EV battery charger is designed with a two-stage charging model to achieve good efficiency. The design is simulated by using MATLAB simulation and compared with the existing model. The simulation results show that the proposed model is superior to the traditional model.
\end{abstract}

Copyright $\odot 2020$ Institute of Advanced Engineering and Science. All rights reserved.

Corresponding Author:

S. George Fernandez,

Department of Electrical and Electronics Engineering,

SRMIST, Chennai, India.

Email: George.electrix@gmail.com

\section{INTRODUCTION}

EV that we see today has stages of improvement and development, after being thoroughly identified useful, it gained such popularity. The maintained changes in EV technologies are important to compete with the dominant IC engines, so as to gain wider deployment. Researchers have been finding improving technologies, especially for the power train, battery and charging infrastructure. Compatible with all the electrical modes, Hybrid Electric Vehicles and can drive up to 40 miles. In converters as half bridge, the electrical stress of semiconductors is modified in full bridge converter, which is further modified until significant reduction is achieved. In full-bridge converters, soft switching is always required and can be implemented. EV battery chargers with unidirectional or bidirectional power flow can be classified as on-board and off-board. Unidirectional charging is a logical first step because it limits hardware requirements, simplifies interconnection issues and reduces the degradation of batteries. The Chevrolet Volt operates mainly as a series of hybrids. The Toyota Prius Plug-in Hybrid is a series parallel hybrid. On the basis of same three basic power train architectures of conventional types of hybrid vehicles; a series of HEVs are powered by electric motors only, whereas a parallel HEVs are powered by both its engine and simultaneously operating electric motors, and a series-parallel hybrid operates in either mode. While a simple plain hybrid vehicle only charges its battery from its engine, a plugged-in hybrid can get a significant amount of energy from external sources to recharge its battery. The battery charger can be on-board or external to the vehicle. The best way to explain the on board charger of the battery is using a rectifier to convert AC power into DC power to charge the battery. The DC power is only required by the battery to charge. There will be limitations in designing the onboard chargers such as the size, weight, cost. The charger of the battery is usually external to the battery. To create a very powerful on board charger, proposed converter is designed in a very accurate and easy way. It also helps easily handling the power capabilities. There is also 
schemes that will reduce the bulkiness and size of the battery. The propulsion system by using AC supply uses this charging method. It also called Reductive Charging method.

\section{LITERATURE SURVEY}

To provide high quality of service to each and every the customers, it is important that the numbers of chargers installed are large. Also for this purpose, it is mandatory to model and design the car in a very significant. MAP also known as Markov Arrival Process unlike the probability distribution method has been used in this proposed scheme. To have the stochastic design of the Electric Vehicle Fast charging infrastructure, a new method that estimates quantitatively has been used up. The methods of data interpretation like using histograms, bar graphs pie chart etc has been used up to collect data. The input data for such interpretations is basically the quantitative empirical data for the proposed modeling scheme. For eg the number of cars that come for charging, the number of slots allotted, the number of slots unoccupied, the time that a vehicle takes to get full charge, etcIn earlier studies and researches, the method that was used was inappropriate because they used to utilize the continuous time data rather than discrete data. Now with this new study, the discrete steps can be analyzed carefully and thus make the converter work nicely. In this paper we have proposed an accurate study based on the observed data involving Markov Arrival Process method in discrete steps. Also, we have taken three moments that are used in probability distribution curve and then studied their correlation with regression along with the observations that are in discrete form and discrete time intervals [1-4]. Studying discrete time method is better than continuous time method has already been proven above work. To develop the plan for expanding the network of station so that PHEV can be easily accepted in the local market thus increasing its market share, the U.S. Department of energy's vehicle technologies office, the national renewable energy laboratory (NREL) and the City of Columbus, ohio, have played a very vital role.

A model called NREL's Electric Vehicle Infrastructure Projection also called EVI-Pro was developed so that the consumers may get attracted to the benefits of electric vehicle and get concerned with the environmental problems and consequently adopt PHEVs. It is revealed through some researches 350 plugs of second level and four hundred plugs of the same level at locations involving nonresidential areas and multi-unit dwellings. It was called Columbus' primary goal of PEVs. This analysis finds that while consumer demand for fast charging is expected to remain low (due to modest anticipated adoption of short-range battery electric vehicles), a minimum level of fast charging coverage across the city is required to ease consumer range anxiety concerns by providing a safety net for unexpected charging events. Sensitivity analyses around some key assumptions have also been performed; of these, consumer preference for PHEV versus $\mathrm{BEV}$ and for their electric driving range, ambient conditions, and availability of residential charging at multi-unit dwellings were identified [5-8]. The most difficult decision that comes in making involves the various communities, individuals, companies, markets, etc. The cost of plug in hybrid electrical vehicle supply equipment and its complexity poses more problems in installing the infrastructure. By having a well-planned low price installation of charging station infrastructure, the customers will like the plug in electric vehicle and will get attracted in purchasing them. The market value will increase and the penetration will be deeper of electric vehicle which will benefit the engineers as well as the investors. The miles driven will be increased electrically which will form a huge base in the market place. The shares of the vehicles in the market and among investors will increase. This will increase the customer base and expand in the market rapidly. Today conventionally the studies focus on increasing the growth of electric vehicles. The rate in which petroleum resources are depleting is alarming. The role of charging infrastructure will help in providing the acceleration for EVs growth. The main objective is the development of charging infrastructure.

Finally the current markets are assessed and the correlation between the public focus and the adoption of Electric Supply equipment is studied. Conclusion of the report ends with a discussion on the methods, operation, planning, impact, economy of the growth of the Plug-in Hybrid Electric Vehicle charging supply equipment and infrastructure [8-12]. The customers should be encouraged to use the fast charging stations not at the high peak hours of the day when large traffic is present. This will also enhance less investment in the waiting spots. The structural profile of loads can be changed of Plug in Hybrid Electric Vehicle. By managing the coordination between the charging spots and waiting spots for the customers, the charging stations can be utilized in a maximum way possible. This will reduce the cost of investment in the project. The new technology called SOMC spot also called single output multiple cables is focused in this paper. The second stage of the proposed model involves a simulation procedure that has certain probability figures, in which coordinated charging is simulated, so that the programming of given charging is considered. The verification of the effectiveness of the given proposed model is studied by researching the residential parking lot. This case study has great potential in reducing the annual investment on the fast charging station based on SOMC spot technology. It will be managed by having a coordination by providing the proper 
charging services [13-17]. With the main focus on maximizing the investment on the infrastructure for charging station this proposed paper displays an optimized based approach which is driven by data. The taxi driver can be spotted and allocated a nearby charging station even when they are stuck in traffic or are travelling in some remote places. For managing the charging traffic and congestions, the given design based on $\mathrm{M} / \mathrm{M} / \mathrm{x} / \mathrm{s}$ queuing theory is adopted so that the probability can be estimated so that the charges of the taxi can be found out at their places in dwell. One of the solver called Garobi Solver can be used to calculate Linear Program of Integers by using regression and logarithmic transformations. These kind of transformations and mathematical relations are used conventionally to allocate the charger. The GPS [18-22] technology that is used in today's world is applied and the data is collected. The following results are the basic findings that are included:

a) The spots of the charging infrastructure is determined by the dwelling structure of the fleet of the taxis.

b) The number of chargers required in the charging stations is reduced and their utilization increases when the places are made for the customer comfort for example the waiting stands for them.

c) The parking spots and the chargers in the fast charging infrastructure are quantified by comparing the installation of as much as chargers possible and the waiting spots for the customers [6]. The given report raises a very important question regarding the need of the Hybrid Electric Vehicle in today's world. The EVSE or the Electric Vehicle Supply equipment which is also called the charging equipment for the Plug in Hybrid Electric Vehicles is an important part of the design and needs a special focus while designing it. The current initiatives are enhanced by analyzing this proposed converter comprehensively which forms a basis for charging infrastructure of PHEV.

Consequently some non-residents networks which are basically the workplaces or public places in the United States of America were analyzed. They gave an estimation required quantitatively. The result was that they finally support the adoption of charging equipment of Electric. The analysis provides guidance to public and private stakeholders who are seeking to provide nationwide charging coverage, improve the EVSE business case by maximizing station utilization, and promote effective use of private/public infrastructure investments. The analysis is organized around the non-residential EVSE network required to meet consumer coverage expectations and to satisfy consumer demand in high-PEV-adoption scenarios. The charging infrastructure needs to be built basically where the people generally travel, at remote places. It can be any type of geographical areas. The main cosmopolitan cities are fundamentally the cities like New York, Beijing, Singapore, and Delhi, Norway etc where they have already adopted various techniques as an attempt to lure citizens in buying the electric vehicle supply [23-25]. Further, a charging method is proposed according to which the person handling the vehicle is instructed to make the energy demand in limit. The execution of the proposed converter system allows the electric vehicle charging stations to handle as much customers without wasting their time standing in the queue The maximum accuracy of the given converter model is analyzed via simulation in MATLAB. Finally, the existing service providers for charging the electric vehicles will be able to use this technology. The future investors that want an efficient design to invest will also be able to understand the need of such design $[8,9]$. Because of the advantages EVs gain more advantage and it the infrastructure need is must [10-12].

\section{EXISTING SYSTEM}

Generally, the most popular topology used in pre-regulators of power factor correction circuit is a boost converter. It is basically due to the boost converters that can have continuous input current that to track down the changes in line voltage using average control techniques in the current mode. The boost converters are manipulated to force the input current. Conventional one stage boost converter is shown in Figure 1. The inductor ripple current $(\Delta \mathrm{IL} 1)$ is directly seen at the converter's input and will require EMI filter to meet certain requirements. The current (I1) at the output of the diode is discontinuous and the capacitor present at the output (Cout) must filter out. The ripple current in the capacitor present at the output (Icout) is very high in this topology and is the difference between I1 and the current (Iout) of the dc output. A conventional single stage boost converter is shown in Figure 1. 


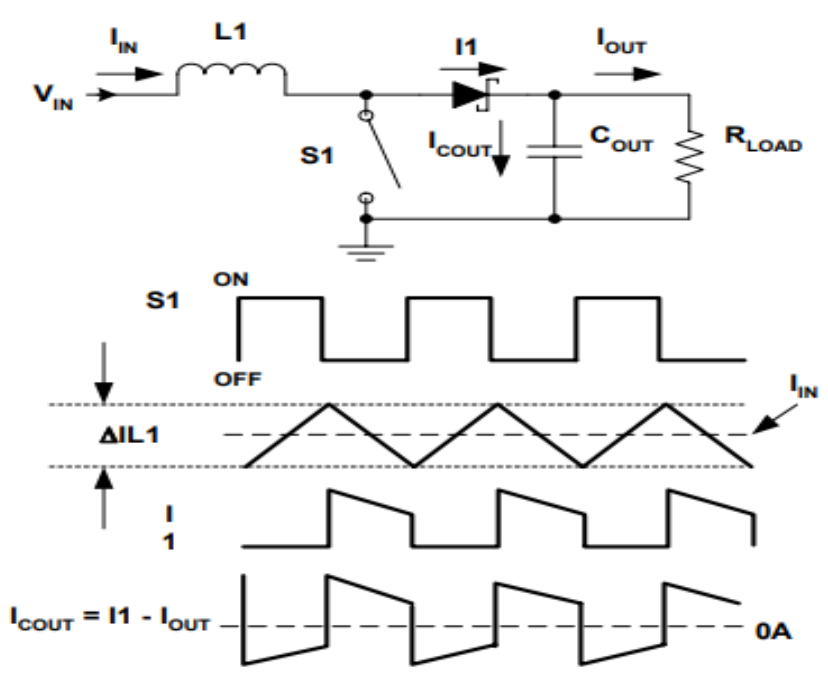

Figure 1. Conventional one stage boost converter

\section{PROPOSED SYSTEM}

The proposed converter circuit diagram is given in Figure 2. For the front-end converter and an isolated full-bridge DC-DC converter used at the back end, an interleaved boost PFC circuit is used in the proposed system. The two parallel CCM boost converters operate out of phase 180 degree. Using the rectifier circuit, the source input ac is converted to dc. The dc input is given to the boost converter that is interleaved. Inherently, the interleaved boost converter uses parallel semiconductors to reduce loss of conductivity. It had two conventional boost PFC converters, each operating at half the load power rating, to design the interleaved PFC converter. The full bridge inverter is used in the circuit with the zero voltage switching. All the semiconductor switches are molded with a capacitor in parallel. The switches of the inverters are working on the diagonal with 50\% duty cycle. A transformer is used to isolate the converter and the load. Through the inverter part, the dc source is converted into ac and it is transferred through the transformer. Another bridge rectifier is used to converter the ac source into the dc source. The output rectifier requires a clamp network consisting of $\mathrm{DC}, \mathrm{RC}$ and $\mathrm{CC}$ to clamp the voltage ring due to the capacitance of the diode junction with the transformer's leakage inductance.

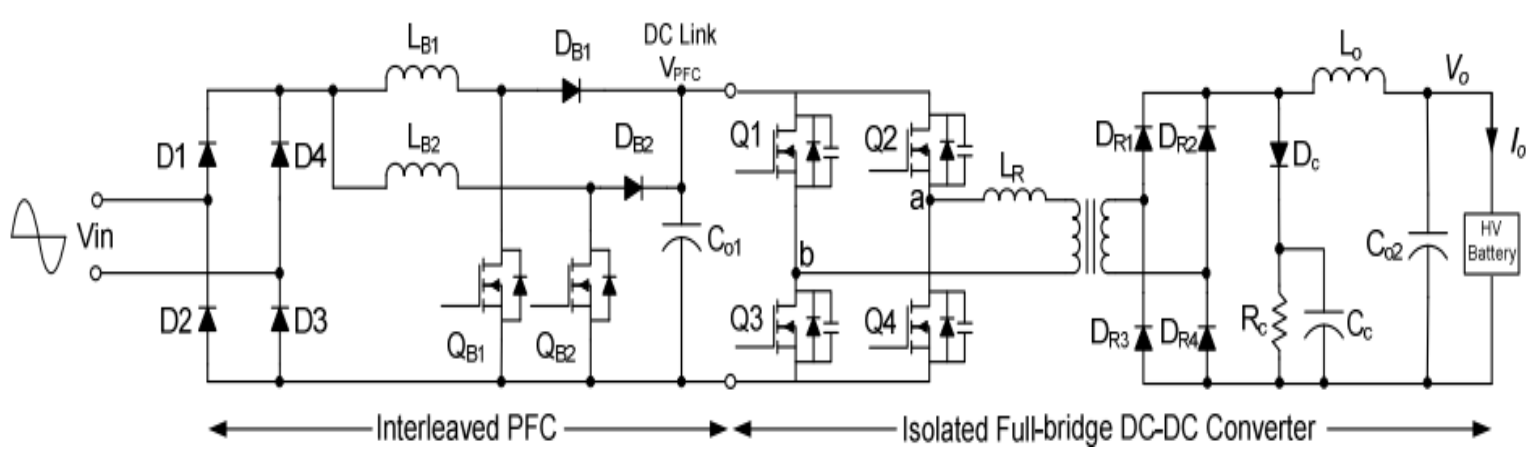

Figure 2. The proposed converter circuit diagram

The Power Factor Correction consists of Constant Current Mode boost converters that are interleaved with each other in parallel, and operate out of phase from each other by 180 degrees. At the input side the inductor currents in L1 and L2 are the sum of total current. The inductor ripple currents cancel each other and thus reduce the ripples in input current as they are 180 degree out of phase. At around 50\% duty cycle, cancellation of inductor current ripples at maximum rate. The sum of the two diode currents in boost converters is the total output capacitor current. The interleaving of converters reduces the ripple current in output capacitor as the function of the duty cycle. 
As the duty cycle increases from 0 to $50 \%$ and so on to $100 \%$, the sum of the two diode currents reaches a constant value as DC. At last only output inductive filter is used to remove the ripples. The front-end ac-dc rectifier is shown in Figure 3 and the circuit to get the desired output DC voltage is given in Figure 4. The charger design and calculations details are provided in this section. Initially, 1 ampere of output current ripple is assumed. The duty cycle loss and dead time loss of MOSFETs was assumed to have a duty ratio equal to 0.75 at starting. Finally, the ratio of primary to secondary turns of the transformer turns is given as :

$$
n_{t}=\frac{D_{e f f} \times V_{i n}}{V_{o}}
$$

which is equal to 0.1125 . Where input voltage Vin $=230 \mathrm{~V}(\mathrm{rms})$ and output voltage Vout $=46 \mathrm{~V}$ DC.

A planar customary ferrite transformer was designed using the transformer turns ratio primary to secondary as 1000:150. The inductor value of was selected using

$$
L_{0}=\frac{\left(\frac{V_{\text {in }}}{n_{t}}-V_{0}\right) \times D_{\text {eff }}}{\Delta I_{d} \times 2 f_{s}}
$$

which is equal to $0.500 \mathrm{uH}$. The value of the inductor Lrconnected in series with the primary of transformer is given by,

$$
L_{R}=\frac{n_{t} \times V_{\text {in }}\left(1-D_{e f f}\right)}{4 \Delta I_{d} \times f_{s}}
$$

which is equal to $80 \mathrm{uH}$. With a snubber capacitor for passive to active leg, $\mathrm{C}=\mathrm{C} 1=\mathrm{C} 2=200 \mathrm{u}$. I critical is given by $\mathrm{Ic}=(\mathrm{V}$ in $)[2(\mathrm{C} \mathrm{PA}) / \mathrm{L} \mathrm{r}] 1 / 2 \sim=23.3 \mathrm{~A}$.

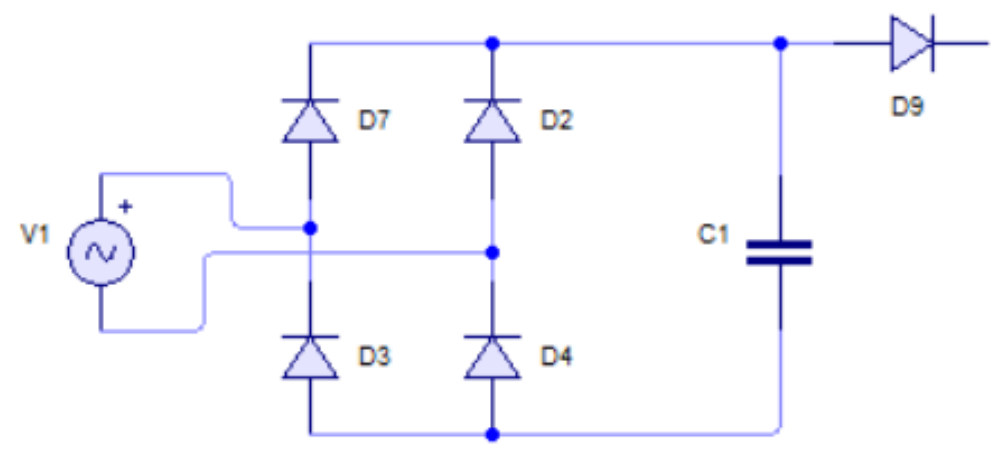

Figure 3. Front end AC-DC rectifier

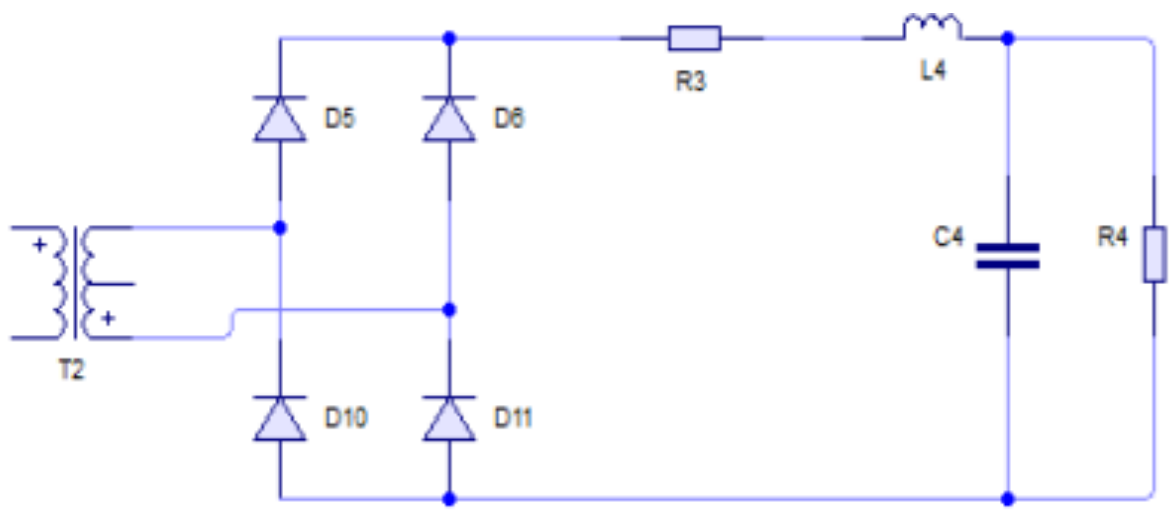

Figure 4. Output rectifier for DC voltage 


\section{RESULTS AND DISCUSSIONS}

Supply Input Voltage is 230 volts which root mean square value. It is given to the converter circuit. The Input voltage simulation in MATLAB is given in the following Figure 5. Output current of the converter is approximately 1.8 amperes. The presented solution to charge the battery has the peak efficiency of around $95 \%$. The design, operation and results of the battery charging are proposed in this paper. Output Voltage is finally achieved to charge the battery. The voltage is around 46 Volts. The Front end converter and the Backend AC-DC converter are isolated via a transformer. The secondary output is shown in Figure 6. The gate pulse of the MOSFET is shown in Figure 7.

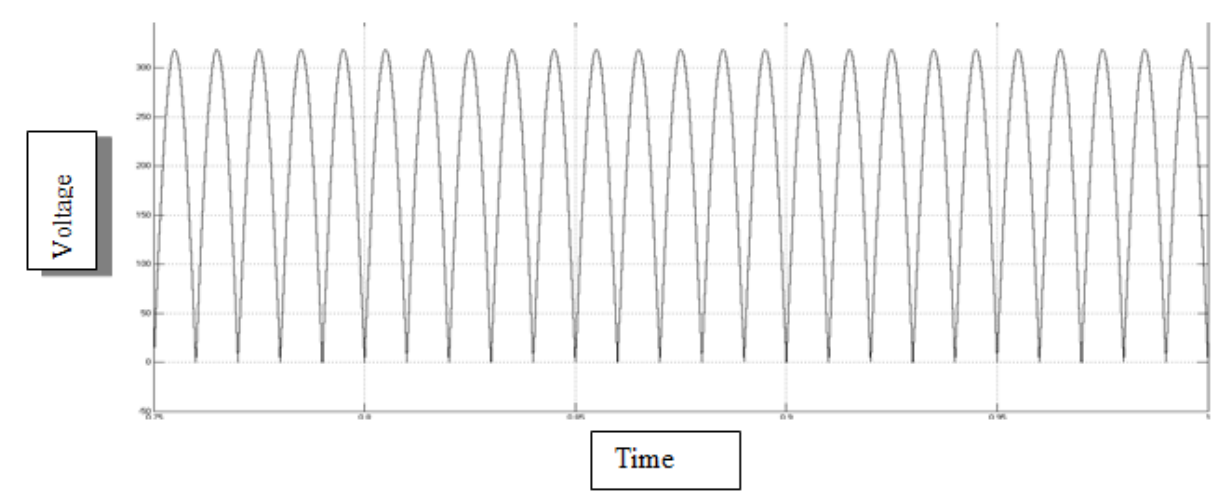

Figure 5. The input supply voltage simulation

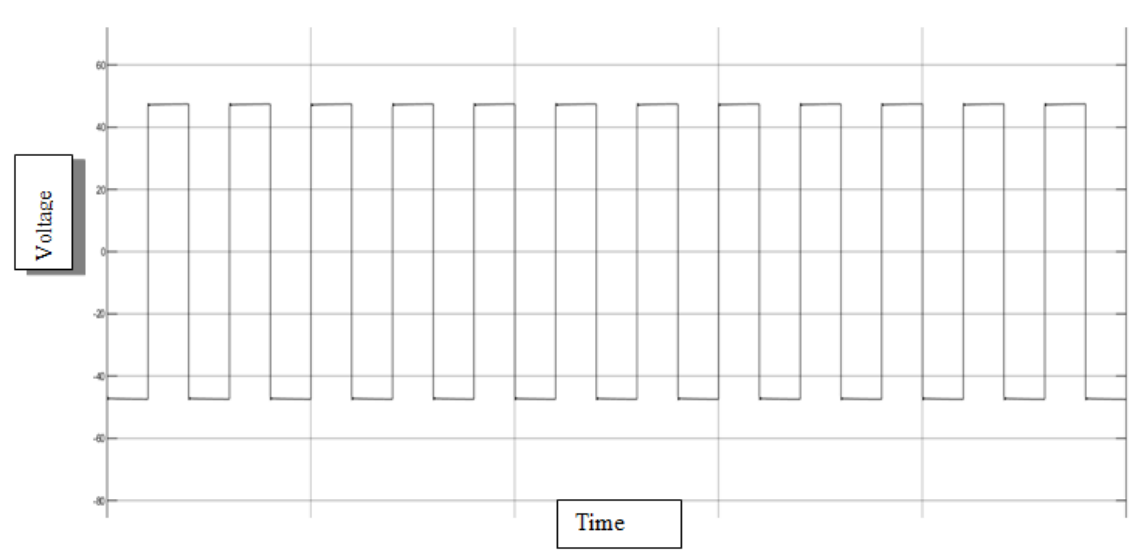

Figure 6. The voltage of secondary winding of transformer

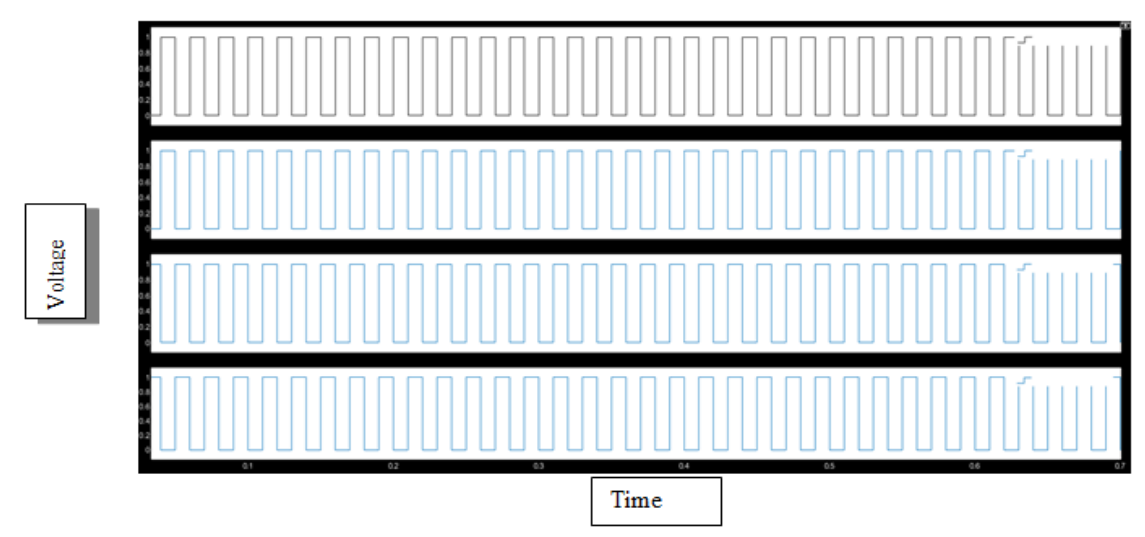

Figure 7. MOSFETs gate pulse 


\section{CONCLUSION}

The desired outcome was observed with each section explained in detailed and the analysis is proved with adequate simulation result. ZVS is executed in the well calculated manner in the full bridge configuration. PWM switching and the synchronizing was the challenge which was successfully understood and individually switched on/off for suitable overlapping of the diagonal MOSFETs of the full-bridge. Since the voltage at the input is fed through sequence of network for various parameters rectification. Inductor values at the primary side of interleaved is calculated and so the leakage inductance for proper zero voltage switching. The output power is then used for charging the battery put at the terminal side. Full bridge is the most acceptable and modifiable configuration converter for industrial application and the investigation about it shows favorable outcomes.

\section{REFERENCES}

[1] S. G. Fernandez, et al., "Essential Need for Electric Vehicles and Infrastructure Advancement: Challenges in India," Indian Journal of Science and Technology, vol. 9, no. 35, p. 101843, 2016.

[2] C. Farkas and M. Ttellek, "Capacity planning of electric car charging station based on discrete time observations and MAP(2)/G/c queue," Periodica Polytechnica Elecrical Engineering Computer Science, vol. 62, no. 3, pp. 82-89, 2018.

[3] E. Wood, et al., "Charging electric vehicles in smart cities: An EVI-pro analysis of Columbus Ohio," National Renewable Energy Laboratory, 2018.

[4] E. Wood, et al., "Regional charging infrastructure for plug-in electric vehicles: A case study of Massachusetts," National Renewable Energy Laboratory, 2017.

[5] H. Zhang, et al., "Optimal planning of PEV charging station with single output multiple cables charging spots," IEEE Transactions on Smart Grid, vol. 8, no. 5, pp. 2119-2128, 2017.

[6] J. Yang, et al., "A data-driven optimization-based approach for siting and sizing of electric taxi charging stations," Transportation Research Part C: Emerging Technologies, vol. 77, pp. 462-477, 2017.

[7] E. Wood, et al., "National plug-in electric vehicle infrastructure analysis," U.S. Department of Energy, Office of Energy Efficiency and Renewable Energy, 2017.

[8] N. Korolvoko, et al., "Modeling and Forecasting Self-Similar Power Load Due to EV Fast Chargers," IEEE Transactions on Smart Grid, vol. 7, no. 3, pp. 1620-1629, 2016.

[9] I. Zenginnis, et al., "Analysis and quality of service evaluation of a fast charging station for electric vehicles," Energy, vol. 112, pp. 669-678, 2016.

[10] G. F. Savari, et al., "Internet of Things based real-time electric vehicle load forecasting and charging station recommendation," ISA Transactions, vol. 97, pp. 431-447, 2020.

[11] D. Sattianadan, et al., "Uninterrupted supply to BLDC motor using PV and grid," International Journal of Recent Technology and Engineering, vol. 8, no. 2S11, pp. 3357-3362, 2019.

[12] D. Berjoza and I. Jurgena, "Analysis of distribution of electric vehicle charging stations in the Baltic," Engineering for Rural Development, vol. 14, pp. 258-264, 2015.

[13] E. X. Q. Yang, "Extended describing function method for small-signal modeling of resonant and multi-resonant converters," Ph.D. dissertation, Virginia Polytechnic Institute and State University, Blacksburg, 1994.

[14] P. Wang, et al., "Modeling and simulation of full-bridge series resonant converter based on generalized state space averaging," in Proceedings of the 2nd International Conference on Computer Science and Electronics Engineering, Atlantis Press, 2013.

[15] S. Dusmez and A. Khaligh, "A compact and integrated multifunctional power electronic interface for plug-in electric vehicles," IEEE Transactions on Power Electronics, vol. 28, no. 12, pp. 5690-5701, 2013.

[16] I. Subotic, et al., "Isolated chargers for EVs incorporating six-phase machines," IEEE Transactions on Industrial Electronics, vol. 63, no. 1, pp. 653-664, 2016.

[17] I. Subotic, et al., "Single-phase on-board integrated battery chargers for EVs based on multiphase machines," IEEE Transactions on Power Electronics, vol. 31, no. 9, pp. 6511-6523, 2016.

[18] M. S. Diab, et al., "A nine-switch-converter-based integrated motor drive and battery charger system for EVs using symmetrical six-phase machines," IEEE Transactions on Industrial Electronics, vol. 63, no. 9, pp. 5326-5335, 2016.

[19] G. Pellegrino, et al., "An integral battery charger with power factor correction for electric scooter," IEEE Transactions on Power Electronics, vol. 25, no. 3, pp. 751-759, 2010.

[20] S. Haghbin, et al., "Grid-connected integrated battery chargers in vehicle applications: Review and new solution," IEEE Transactions on Industrial Electronics, vol. 60, no. 2, pp. 459-473, 2013.

[21] G. F. Savari, et al., "Optimal Charging Scheduling of Electric Vehicles in Micro Grids Using Priority Algorithms and Particle Swarm Optimization," Mobile Networks and Applications, vol. 24, pp. 1835-1847, 2019.

[22] D. Sattianadan, "Techno Economic Evaluation of a Hybrid energy system," International Journal of Recent Technology and Engineering, vol. 8, no. 2S11, pp. 2575-2579, 2019.

[23] K. A. Maidalailu, "Modeling and Simulation of Dynamic Voltage Restorer (DVR) Using ZSI for Mitigation of Voltage Sags/Swells," International Journal of Applied Engineering Research, vol. 10, no. 44, 2015.

[24] P. Suresh, et al., "Reduction of Transient Voltages in Switches using Embedded Machine Learning," International Journal of Power Electronics and Drive Systems, vol. 11, no. 1, pp. 235-241, Mar 2020.

[25] R. Palanisamy and K. Vijayakumar, "Maximum boost control for 7-level Z-source cascaded H-bridge inverter," International Journal of Power Electronics and Drive System (IJPEDS), vol. 8, no. 2, pp. 739-746, 2017. 